\title{
LncRNA NEAT1 promotes apoptosis and inflammation in LPS-induced sepsis models by targeting miR-590-3p
}

\author{
LINGLING LIU ${ }^{1}$, FENGTAO LIU ${ }^{2}$, ZHILU SUN ${ }^{1}$, ZHENGLIANG PENG ${ }^{1}$, TING YOU ${ }^{1}$ and ZIYING YU $^{1}$ \\ ${ }^{1}$ Emergency Department, First Affiliated Hospital of the University of South China, Hengyang, Hunan 421001; \\ ${ }^{2}$ Center of Functional Laboratory, Hengyang Medical College, University of South China, Hengyang, Hunan 421001, P.R. China
}

Received August 22, 2019; Accepted July 14, 2020

DOI: $10.3892 /$ etm.2020.9079

\begin{abstract}
Sepsis is a complication of infection caused by disease or trauma. Increasing evidence have shown that long noncoding RNAs (lncRNAs) are involved in the regulation of sepsis. However, the mechanism of IncRNA nuclear enriched abundant transcript 1 (NEAT1) in the regulation of sepsis progression remains to be elucidated.Lipopolysaccharide(LPS) was used to induce a sepsis cell model. The expression levels of NEAT1 and microRNA (miR)-590-3p were determined by reverse transcription-quantitative PCR. Cell viability and apoptosis were detected using Cell Counting Kit-8 (CCK-8) assay and flow cytometry, respectively. Western blot analysis was performed to evaluate the levels of apoptosis- and NF- $\kappa \mathrm{B}$ signaling pathway-related proteins. The concentration of inflammatory cytokines was determined using ELISA. In addition, dual-luciferase reporter assay, RNA immunoprecipitation and biotin-labeled RNA pull-down assay were performed to verify the interaction between NEAT1 and miR-590-3p. The results showed that NEAT1 was highly expressed in patients with sepsis and LPS-induced H9c2 cells. Knockdown of NEAT1 decreased LPS-induced cell apoptosis and inflammation response in H9c2 cells. Meanwhile, miR-590-3p showed decreased expression in sepsis, and its overexpression could relieve LPS-induced H9c2 cell damage. Further experiments revealed that NEAT1 could sponge miR-590-3p. Knockdown of miR-590-3p reversed the inhibitory effect of NEAT1 knockdown on LPS-induced H9c2 cell damage. Additionally, the NEAT1/miR-590-3p axis could regulate the activity of the NF- $\kappa$ B signaling pathway. To conclude, lncRNA NEAT1 accelerated apoptosis and inflammation in LPS-stimulated H9c2 cells via sponging miR-590-3p. These findings may provide a new strategy for the treatment of sepsis.
\end{abstract}

Correspondence to: Ms. Ziying Yu, Emergency Department, First Affiliated Hospital of the University of South China, 69 Chuanshan Road, Shigu, Hengyang, Hunan 421001, P.R. China

E-mail: yuziyingnh@163.com

Key words: sepsis, nuclear enriched abundant transcript 1, microRNA-590-3p, lipopolysaccharide, apoptosis, inflammation

\section{Introduction}

Sepsis is a syndrome caused by infection that causes systemic inflammation, which could cause cell apoptosis, inflammation and oxidative stress (1-3). The high mortality rates of sepsis has become a worldwide issue (4), making it urgent to find key targets for sepsis treatment. Lipopolysaccharide (LPS) is an endotoxin that combines with toll-like receptor 4 (TLR4) on the surface of the cell membrane to achieve cellular inflammatory response (5). LPS induces NF- $\mathrm{NB}$ signaling pathway activation in podocytes and promotes the levels of pro-inflammatory cytokines, such as interleukin (IL)-6, tumor necrosis factor- $\alpha$ (TNF- $\alpha$ ) and IL-1 $\beta(5,6)$. Therefore, LPS can be used to induce cell inflammatory response to construct sepsis cell models.

Long non-coding RNAs (lncRNAs) are a class of noncoding RNAs that are $>200$ nucleotides in length which are involved in the regulation of various diseases $(7,8)$. Nuclear enriched abundant transcript 1 (NEAT1) is a cancer-related lncRNA which exerts vital effects on innate immune responses $(9,10)$. NEAT1 has been shown to be associated with immunosuppression (11), brain injury (12), prognosis (13) and kidney injury (14) in sepsis. Therefore, NEAT1 expression could be used as a marker in sepsis diagnosis (15), but its specific mechanism remains to be elucidated.

MicroRNAs (miRs/miRNAs) are small non-coding RNAs, which plays a role in post-transcriptional regulation via binding with target genes $(16,17)$. At present, it has been proven that numerous miRNAs can regulate the process of sepsis, such as miR-145 (18), miR-150 (19) and miR-25 (20). Studies have shown that miR-590-3p plays a key role in the control of various cancers and associated with the activation of multiple signaling pathways (21-23). Zhao et al (24), reported that miR-590-3p could target the NF- $\kappa \mathrm{B}$ signaling pathway to regulate the inflammation of myocarditis. Another study suggested that miR-590-3p could relieve oxidative stress in ischemia-reperfusion injury mice models by regulating the $\mathrm{NF}-\kappa \mathrm{B}$ signaling pathway (25). Recent studies have shown that the NF- $\kappa \mathrm{B}$ signaling pathway is closely associated with cell apoptosis and involved in the transcriptional regulation of various apoptosis-related genes, playing a decisive role in the process of apoptosis $(26,27)$. Therefore, $N F-\kappa B$ is one of the important downstream signaling pathways regulated by miR-590-3p. However, to the best of our knowledge, there are few studies investigating the role of miR-590-3p in sepsis. 
The present study aimed to investigate the mechanism of NEAT1 in an LPS-induced sepsis cell model. Knockdown of NEAT1 reduced apoptosis and inflammatory response in LPS-induced H9c2 cells. The regulatory function of NEAT1 on sepsis may be achieved partly by targeting miR-590-3p. The discovery of the NEAT1/miR-590-3p axis may contribute to the development of new targets for sepsis treatment.

\section{Materials and methods}

Serum sample collection. Blood from 22 patients with sepsis and 22 healthy volunteers were collected at the First Affiliated Hospital of the University of South China between March 2016 to June 2018. The clinical characteristics of the enrolled subjects are shown in Table I. All volunteers signed informed consent to the study. The present study was approved by the Ethics Committee of First Affiliated Hospital of the University of South China.

Cell culture and LPS treatment. Cardiomyocytes (H9c2 cells) were purchased from Shanghai Jining Shiye Co., Ltd., and maintained in DMEM (Beijing Solarbio Science \& Technology Co., Ltd.) supplemented with 10\% FBS (Thermo Fisher Scientific, Inc.) and $1 \%$ penicillin/streptomycin (Thermo Fisher Scientific, Inc.) at $37^{\circ} \mathrm{C}$ in an incubator containing $5 \% \mathrm{CO}_{2}$. Cells were treated with 5 or $10 \mu \mathrm{g} / \mathrm{ml}$ LPS (Beijing Solarbio Science \& Technology Co., Ltd.) at $37^{\circ} \mathrm{C}$ for $12 \mathrm{~h}$ to induce sepsis cell models as previously described $(28,29)$.

Cell transfection. Small interfering RNA (siRNA) against NEAT1 (si-NEAT1; 5'-GAGCAATGACCCCGGTGACG-3') and its control(si-negative control (NC); 5'-TAGATACCCCCA GGCCTACC-3'), pcDNA3.1 overexpressing NEAT1 vector (pcDNA-NEAT1; forward (F), 5'-TTGGGACAGTGTGG-3' and reverse (R), 5'-TCAGTCCAGCAGGCA-3') and its control (pcDNA-NC; 5'-TAGAAGGCACAGTCGAGG-3'), miR-590-3p mimic or inhibitor (miR-590-3p; 5'-UAAUUU UAUGUAUAAGCUAGU-3' or anti-miR-590-3p; 5'-ACU AGCUUAUACAUAAAAUUA-3') and their controls (NC; 5'-CGAUCGCAUCAGCAUCGAUUGC-3' or anti-NC; 5'-CAGUACUUUUGUGUAGUACAA-3') were synthesized by Vigene Biosciences. H9c 2 cells transfection was performed using Lipofectamine ${ }^{\mathrm{TM}} 3000$ (Invitrogen; Thermo Fisher Scientific, Inc.). Briefly, H9c2 cells were seeded in six-well plates at a density of $1 \times 10^{5}$ cells/well. Oligonucleotides $(20 \mathrm{nM})$ or vectors $(2 \mathrm{mg} / \mathrm{ml})$ were transfected into cells when cells reached $60 \%$ confluence. Following incubation for $24 \mathrm{~h}$ at $37^{\circ} \mathrm{C}$, the medium was changed and $10 \mu \mathrm{g} / \mathrm{ml} \mathrm{LPS}$ was added to the cells for $12 \mathrm{~h}$. Subsequently, the cells were collected for functional assays. In addition, cells that were not treated with LPS (control group) were collected at $48 \mathrm{~h}$ after transfection and the transfection efficiencies of miRNA mimics, inhibitors, siRNAs and overexpression vectors were evaluated by detecting the expression of NEAT1 and miR-590-3p.

Reverse transcription-quantitative PCR (RT-qPCR). TRIzol ${ }^{\circledR}$ reagent (Invitrogen; Thermo Fisher Scientific, Inc.) was used to isolate total RNA from serum samples and treated H9c2 cells. RNA was reverse transcribed into cDNA using a cDNA reverse
Table I. Clinical characteristics of enrolled subjects.

\begin{tabular}{lccc}
\hline Characteristics & Healthy volunteers & Sepsis & P-value \\
\hline Number & 22 & 22 & - \\
Age (years) & $50.20 \pm 18.4$ & $51.40 \pm 16.8$ & $>0.05$ \\
Sex (male/female) & $12 / 10$ & $12 / 10$ & $>0.05$ \\
WBC $\left(x 10^{9} / 1\right)$ & $6.35 \pm 1.27$ & $14.12 \pm 5.35$ & $<0.01$ \\
APACHEII score & - & $17.30 \pm 4.60$ & $<0.01$ \\
Lac $(\mathrm{mmol} / \mathrm{l})$ & $0.49 \pm 0.02$ & $4.02 \pm 1.98$ & $<0.01$ \\
CRP $(\mu \mathrm{g} / \mathrm{l})$ & $1.98 \pm 1.21$ & $18.12 \pm 4.33$ & $<0.01$ \\
\hline
\end{tabular}

WBC, white blood cell count; APACHEII, acute physiology, age and chronic health evaluation II; Lac, lactic acid; CRP, C-reaction protein.

transcription kit (Invitrogen; Thermo Fisher Scientific, Inc.) at the following conditions: $37^{\circ} \mathrm{C}$ for $1 \mathrm{~h}$ and $85^{\circ} \mathrm{C}$ for $5 \mathrm{~min}$. Gene amplifications was conducted on a StepOnePlus thermocycler (Thermo Fisher Scientific, Inc.) using SYBR Green (Invitrogen; Thermo Fisher Scientific, Inc.) according to the manufacturer's instructions. The relative expression of NEAT1 or miR-590-3p was normalized to endogenous GAPDH or U6 expression, respectively. The following primer pairs were used for the qPCR: NEAT1 F, 5'-TTGGGACAGTGTGG-3' and R, 5'-TCAGTCCAGCAGGCA-3'; GAPDH F, 5'-AGGTCG GTGTGAACGGATTTG-3' and R, 5'-TGTAGACCA TGTAGTTGAGGTCA-3'; miR-590-3p F, 5'-GCCAGTCAG AAATGAGCTTATTC-3' and R, 5'-GCTGCATGTTTC AATCAGAGAC-3' and U6 F, 5'-AAAGACCTGTACGCC AACAC-3' and R, 5'-GTCATACTCCTGCTTGCTGAT-3'. Relative expression of genes was normalized by GAPDH or U6 and was determined using the $2^{-\Delta \Delta C q}$ method (30). The thermocycling conditions used for the qPCR were as follows: Initial denaturation at $95^{\circ} \mathrm{C}$ for $30 \mathrm{sec}$; followed by 40 cycles of $95^{\circ} \mathrm{C}$ for $5 \mathrm{sec}, 55^{\circ} \mathrm{C}$ for $30 \mathrm{sec}$ and $72^{\circ} \mathrm{C}$ for $30 \mathrm{sec}$.

Cell Counting Kit-8 (CCK-8) assay. H9c2 cells were cultured for $24 \mathrm{~h}$ after transfection. According to the manufacturer's protocol, H9c2 cells were washed with PBS and incubated with CCK-8 solution (Glp Bio Technology) for $4 \mathrm{~h}$ in the dark. The absorbance of cells at $450 \mathrm{~nm}$ was observed under a microplate reader (Molecular Devices, LLC).

Cell apoptosis assay. The FITC-Annexin V Apoptosis Detection kit (BD Biosciences) was used to measure cell apoptosis. Briefly, H9c2 cells were digested with trypsin (Beyotime Institute of Biotechnology) and collected into centrifuge tubes. Following washing with cold PBS, the cells were resuspended in 1X Binding Buffer. Subsequently, the cells were stained with $5 \mu \mathrm{l}$ FITC-Annexin $\mathrm{V}$ and $5 \mu \mathrm{l}$ propidium iodide for $15 \mathrm{~min}$ in the dark. Finally, Attune NxT Flow Cytometer (Thermo Fisher Scientific, Inc.) was used to detect fluorescence signals and evaluate cell apoptosis.

Western blot (WB) analysis. Total protein was extracted using RIPA lysis buffer (Santa Cruz Biotechnology, Inc.) and quantified using a bicinchoninic acid protein assay kit (Pierce; Thermo Fisher Scientific, Inc.). Subsequently, 
A

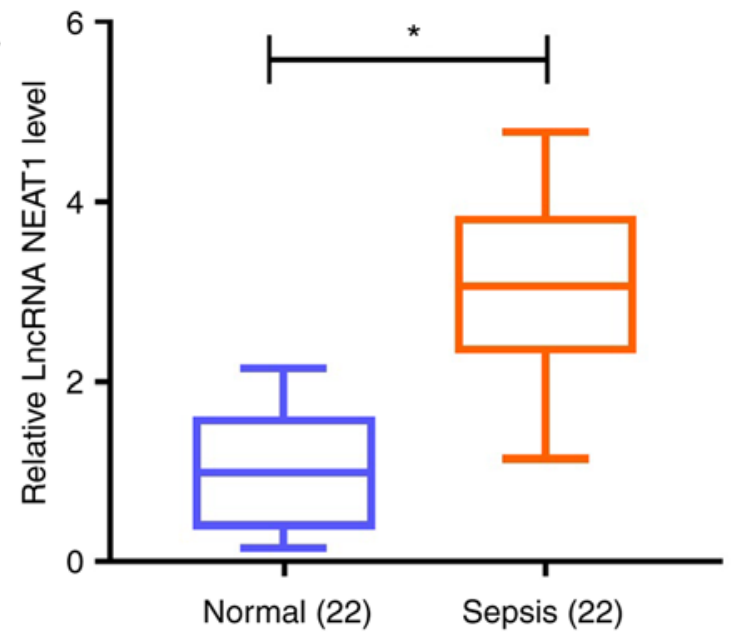

B

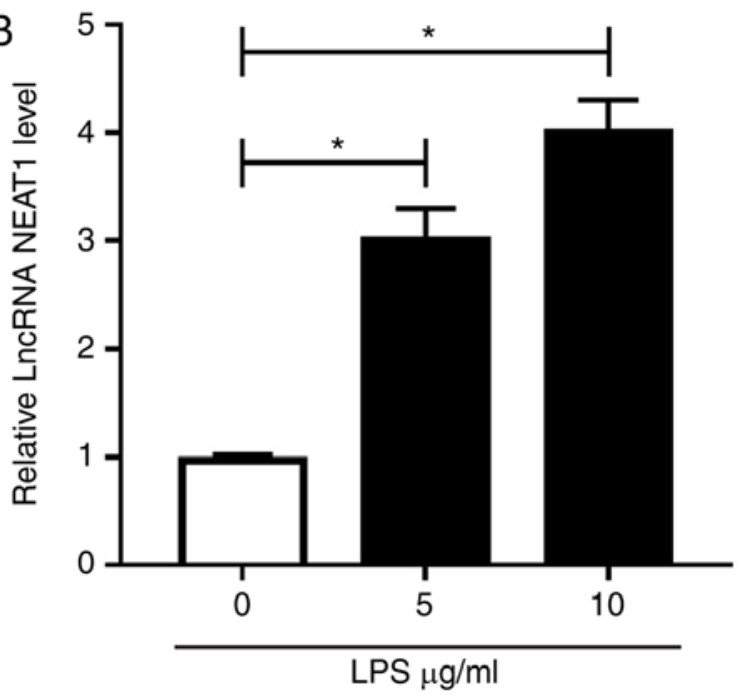

Figure 1. NEAT1 is highly expressed in patients with sepsis and LPS-induced H9c2 cells. (A) NEAT1 expression in patients with sepsis and healthy volunteers were measured by RT-qPCR. (B) Following treatment with 0,5 and $10 \mu \mathrm{g} / \mathrm{ml}$ LPS in H9c2 cells, RT-qPCR was used to detect the expression of NEAT1. "P<0.05. LncRNA, long non-coding RNA; NEAT1, nuclear enriched abundant transcript 1; LPS, lipopolysaccharide; RT-qPCR, reverse transcription-quantitative PCR.

$30 \mu \mathrm{g}$ protein sample was separated by $10 \%$ SDS-PAGE (Beyotime Institute of Biotechnology) and transferred to PVDF membranes (EMD Millipore). Membranes were blocked in 5\% non-fat milk for $2 \mathrm{~h}$ at room temperature and incubated with primary antibodies overnight at $4^{\circ} \mathrm{C}$. Primary antibodies against Bcl-2 (1:500; cat. no. BA0412), Bax (1:1,000; cat. no. BA0315-2), caspase 3 (1:1,000; cat. no. BA3257), TNF receptor associated factor 6 (TRAF6; 1:1,500; cat. no. A00185), phosphorylated (p)-p65 (1:1,000; cat. no. P00284), p65 (1:2,000; cat. no. A00284) and GAPDH (1:2,000; cat. no. BA2913) were purchased from Wuhan Boster Biological Technology, Ltd. Membranes were then incubated with horseradish peroxidase-labeled secondary antibody (1:5,000; cat no. BA1056; Wuhan Boster Biological Technology, Ltd.) for $1 \mathrm{~h}$ at room temperature. Protein signals were visualized using chemiluminescence reagent (EMD Millipore) and captured using Invitrogen iBright 1500 (Thermo Fisher Scientific, Inc.). Results were analyzed using ImageLab software (Version 5.0, Bio-Rad Laboratories, Inc.).

ELISA. TNF- $\alpha$ (kt30484), IL-6 (BA23048), IL-9 (kt30445), and IL-1 $\beta$ (kt30375) ELISA kits (Wuhan Merck Biotechnology Co., Ltd.) were used to measure TNF- $\alpha$, IL-6, IL-9, and IL-1 $\beta$ concentration in cells according to the manufacturer's instructions.. In brief, the cell medium was collected and the supernatant was collected after being centrifuged with $2,000 \mathrm{x}$ g for $10 \mathrm{~min}$ at $4^{\circ} \mathrm{C}$. Standards and tested samples were configured and added to corresponding plates according to the kit instructions. Following incubation at $37^{\circ} \mathrm{C}$ for $30 \mathrm{~min}$, the plates were washed with washing liquid. Subsequently, $50 \mu 1$ enzyme-labeled reagent was added to each well for further incubation for $30 \mathrm{~min}$. Following washing, color developer was added into each well and incubated for $15 \mathrm{~min}$, and termination solution was added into each well. The absorbance at a wavelength of $450 \mathrm{~nm}$ was measured with a microplate reader, a standard curve was drawn, and TNF- $\alpha$, IL- 6 , IL-9, and IL-1 $\beta$ concentration in cells were calculated separately.
Dual-luciferase reporter assay. The StarBase v2.0 tool (http://starbase.sysu.edu.cn/) was used to predict the binding sites between NEAT1 and miR-590-3p. NEAT1 wild-type (NEAT1-wt) or NEAT1 mutated type (NEAT1-mut) reporter vectors were synthesized by General Biosystems. H9c2 cells were inoculated in 24 -well plates $\left(8 \times 10^{4}\right.$ cells/well $)$ and co-transfected with miR-590-3p mimic or miR-NC and NEAT1-wt or NEAT1-mut using LipofectamineÔ 3000 (Invitrogen; Thermo Fisher Scientific, Inc.). Using the dual-luciferase reporter assay kit (Shanghai Genomeditech Biotechnology Co., Ltd.), the Firefly luciferase reaction intensity (RLU1) and Renilla luciferase reaction intensity (RLU2) were determined following transfection for $48 \mathrm{~h}$. The luciferase activity of cells was the ratio of the two groups of data (RLU1/RLU2).

RNA immunoprecipitation (RIP) assay. A Magna RIP kit (EMD Millipore) was used to evaluate the binding degree of NEAT1 and miR-590-3p to protein argonaute-2 (Ago2). Cells were washed with pre-cooled PBS and collected into an Eppendorf tube. Following centrifugation at $377 \mathrm{x}$ g at $4^{\circ} \mathrm{C}$ for 5 min, the cells were lysed with RIP buffer (EMD Millipore) for $5 \mathrm{~min}$. The magnetic beads were pre-incubated with Ago2 antibodies (anti-Ago2; 1:50; cat. no. ab186733; Abcam) and immunoglobulin $\mathrm{G}(\mathrm{IgG})$ antibody (anti-IgG; 1:100; cat. no. ab48386; Abcam). Subsequently, cell lysates were added into the magnetic beads mixture and incubated overnight at $4^{\circ} \mathrm{C}$. RT-qPCR was used to measure the enrichment of NEAT1 and miR-590-3p to anti-Ago2 and anti-IgG.

Biotin-labeled RNA pull-down assay. Biotin-labeled miR-590-3p (Bio-miR-590-3p) and control probe Bio-NC were purchased from Sangon Biotech Co., Ltd. H9c2 cells were transfected with these probes for $24 \mathrm{~h}$ and then lysed to collect the cell lysates. The cell lysates were incubated with streptavidin-labeled magnetic beads (Purimag Biotech Ltd.) overnight at $4^{\circ} \mathrm{C}$. Relative NEAT1 enrichment was detected using RT-qPCR. 

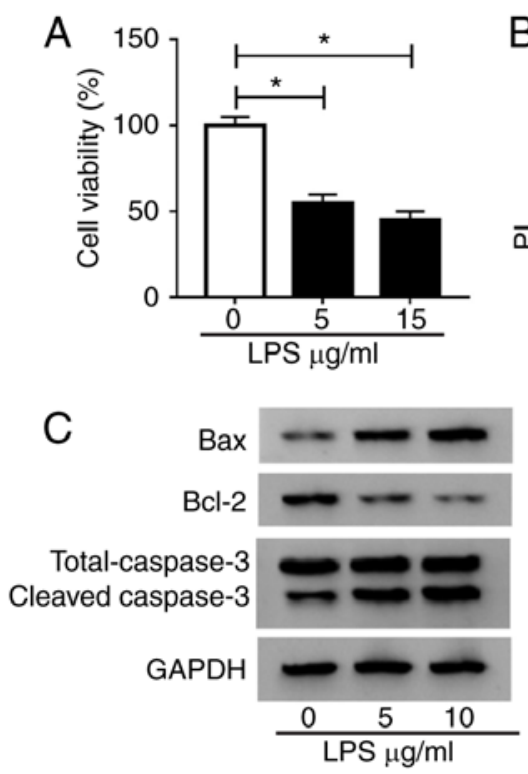

E

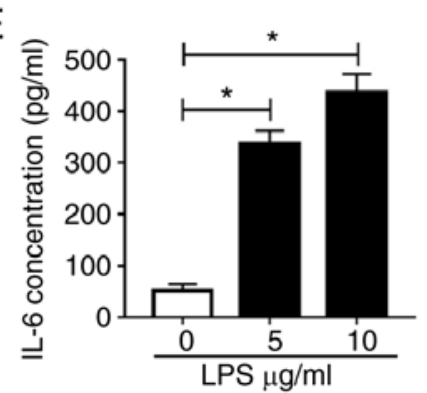

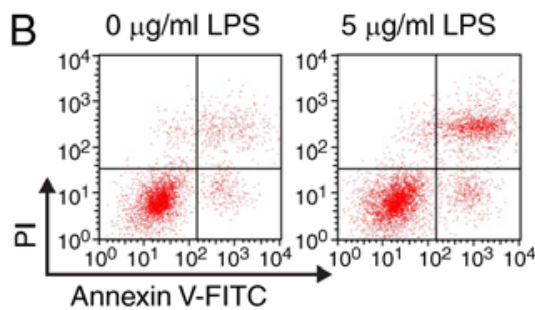
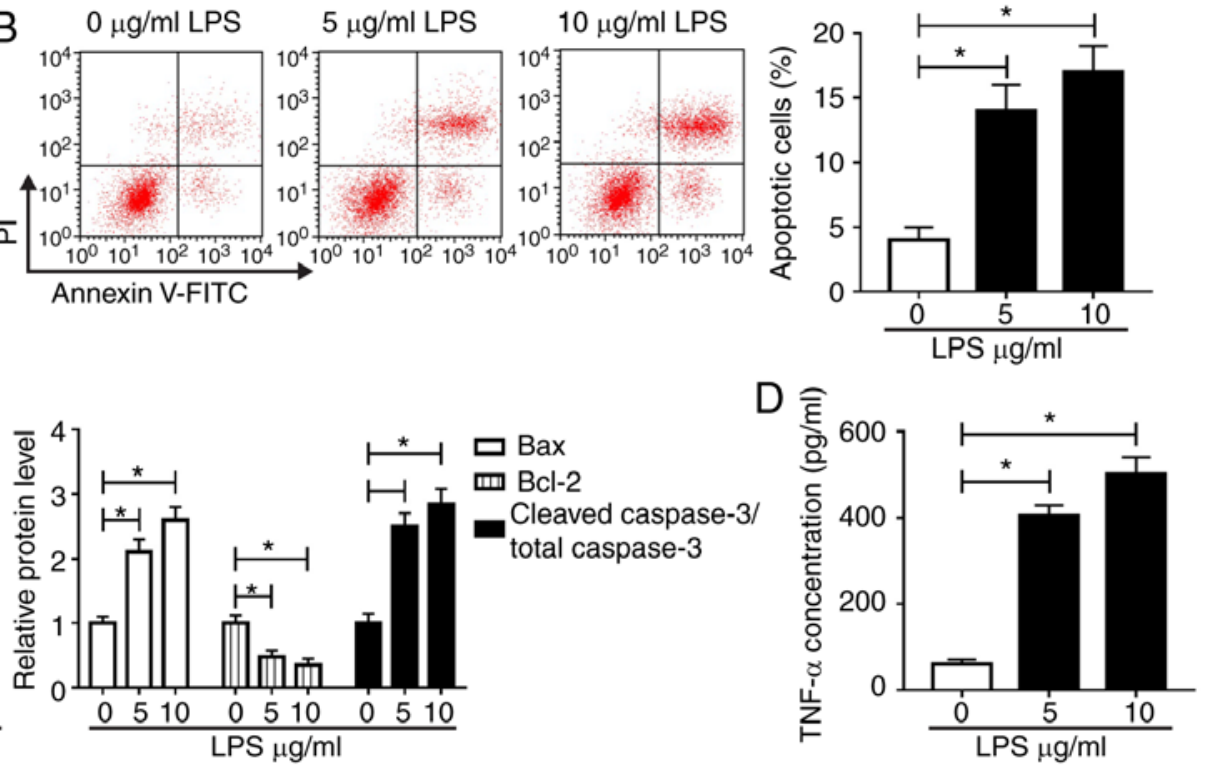

$\mathrm{F}$
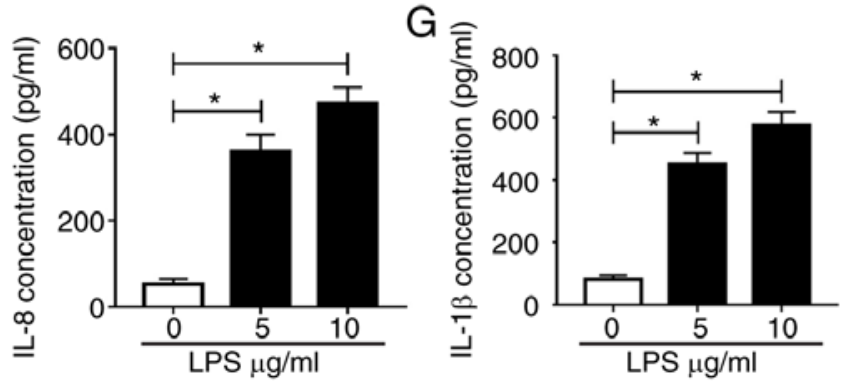

Figure 2. LPS induces H9c2 cell damage. H9c2 cells were treated with 0,5 and $10 \mu \mathrm{g} / \mathrm{ml}$ LPS. Cell viability, apoptosis and apoptosis-related protein expression were measured using (A) Cell Counting Kit-8 assay, (B) flow cytometry and (C) western blot analysis, respectively. ELISA was performed to determine the concentrations of (D) TNF- $\alpha$, (E) IL-6, (F) IL-8 and (G) IL-1 $\beta$ in H9c2 cells. "P<0.05. LPS, lipopolysaccharide; TNF, tumor necrosis factor; IL, interleukin; PI, propidium iodide.

Statistical analysis. Data are presented as the mean $\pm \mathrm{SD}$. Experiments were repeated three times independently. Statistical analysis was performed using GraphPad Prism v7.0 (GraphPad Software, Inc.). Student's t-test or one-way ANOVA followed by Tukey's post-hoc test was used for data comparison. $\mathrm{P}<0.05$ was considered to indicate a statistically significant difference.

\section{Results}

NEAT1 is highly expressed in patients with sepsis and LPS-induced H9c2 cells. First, NEAT1 expression in the serum of patients with sepsis and LPS-induced sepsis cell models was examined. Compared with normal controls, NEAT1 was significantly upregulated in patients with sepsis (Fig. 1A). Similarly, NEAT1 was highly expressed in H9c2 cells treated with 5 and $10 \mu \mathrm{g} / \mathrm{ml}$ LPS compared with in the control group, as detected using RT-qPCR (Fig. 1B). These data indicated that NEAT1 might play a role in sepsis progression.

LPS can induce H9c2 cell apoptosis and inflammation. To verify the success of the sepsis cell model, the biological function of cells was assessed. Compared with controls, CCK-8 assay results showed that LPS significantly reduced H9c2 cell viability (Fig. 2A), and flow cytometry results proved that the number of apoptotic cells significantly increased in LPS-induced H9c2 cells (Fig. 2B). Moreover, WB analysis was performed to measure the levels of apoptosis-related proteins. It was found that Bax and cleaved caspase-3 levels significantly increased, while Bcl-2 levels significantly decreased in LPS-induced H9c2 cells compared with controls, suggesting that LPS could accelerate H9c2 cell apoptosis (Fig. 2C). In addition, ELISA was performed to detect the concentrations of TNF- $\alpha$, IL-6, IL-8 and IL-1 $\beta$ in LPS-induced H9c2 cells. The results showed that the concentrations of TNF- $\alpha$, IL-6, IL-8 and IL-1 $\beta$ significantly increased in $\mathrm{H} 9 \mathrm{c} 2$ cells treated with 5 and $10 \mu \mathrm{g} / \mathrm{ml}$ LPS compared with controls (Fig. 2D-G). These results suggested that LPS could induce cell apoptosis and inflammation, confirming the successful establishment of a sepsis cell model. In addition, the impact $10 \mu \mathrm{g} / \mathrm{ml}$ LPS caused a greater degree of damage to the cells than that of $5 \mu \mathrm{g} / \mathrm{ml}$; therefore, $10 \mu \mathrm{g} / \mathrm{ml}$ was adopted for subsequent tests.

Knockdown of NEAT1 relieves LPS-induced H9c2 cell damage. Since high NEAT1 expression was observed in the LPS-induced sepsis model, a NEAT1 loss-of-function experiment was conducted to verify the effect of NEAT1 on sepsis. The low expression of NEAT1 in H9c2 cells confirmed the transfection efficiency of si-NEAT1 (Fig. S1A). Subsequently, H9c2 cells were transfected with si-NEAT1 or si-NC for $12 \mathrm{~h}$, 


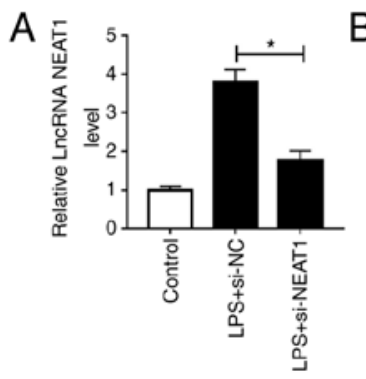

D

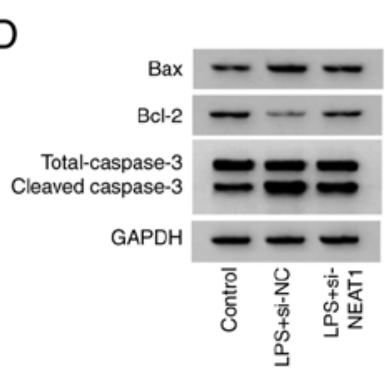

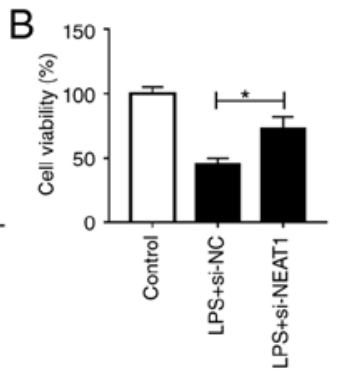
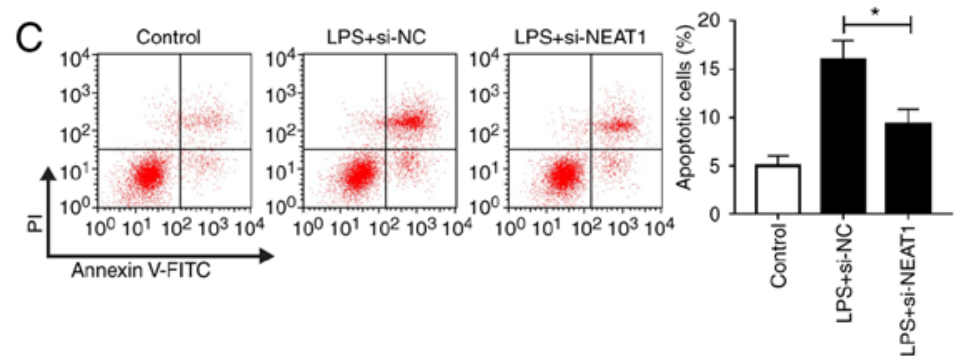

$\mathrm{F}$

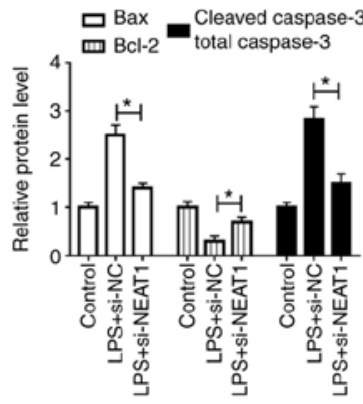

$\mathrm{E}$
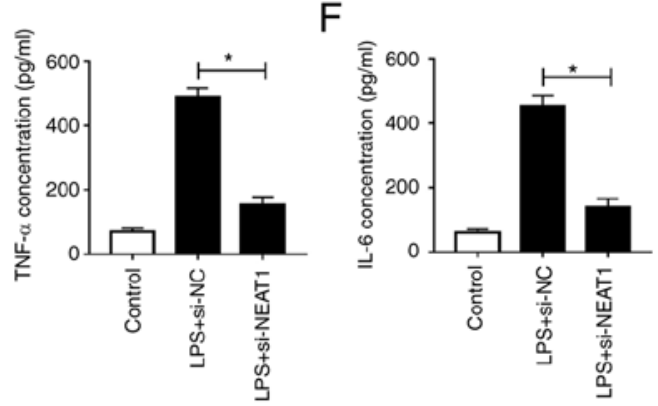
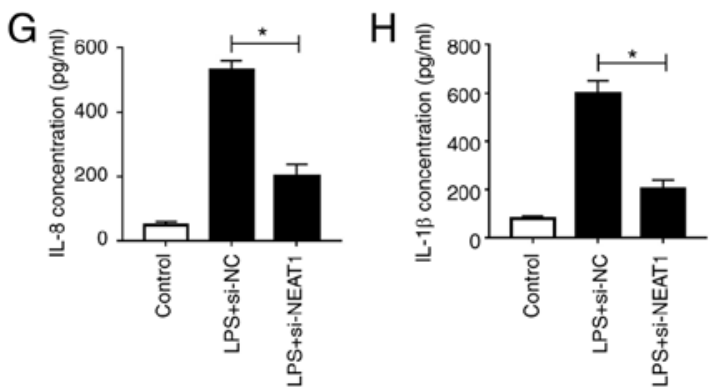

Figure 3. Knockdown of NEAT1 relieves LPS-induced H9c2 cell damage. H9c2 cells were transfected with si-NEAT1 or si-NC for 24 h, followed by stimulation with LPS $(10 \mu \mathrm{g} / \mathrm{ml})$ for $12 \mathrm{~h}$. (A) NEAT1 expression was measured using reverse transcription-quantitative PCR to evaluate the transfection efficiency of si-NEAT1. (B) Cell Counting Kit-8 assay, (C) flow cytometry and (D) western blot analysis were performed to detect cell viability, apoptosis and apoptosis-related protein expression in H9c2 cells, respectively. The concentrations of (E) TNF- $\alpha$, (F) IL-6, (G) IL-8 and (H) IL-1 $\beta$ were determined using ELISA. "P<0.05. LPS, lipopolysaccharide; TNF, tumor necrosis factor; IL, interleukin; PI, propidium iodide; NEAT1, nuclear enriched abundant transcript 1; si-NEAT1, small interfering RNA targeting NEAT1; NC, negative control; lncRNA, long non-coding RNA.

followed by treatment with $10 \mu \mathrm{g} / \mathrm{ml}$ LPS for $12 \mathrm{~h}$. RT-qPCR results showed that si-NEAT1 significantly inhibited NEAT1 expression compared with si-NC transfection (Fig. 3A). CCK-8 assay results showed that NEAT1 knockdown significantly increased the viability of LPS-induced H9c2 cells compared with si-NC transfection (Fig. 3B). Flow cytometry results revealed that NEAT1 silencing significantly suppressed apoptosis in LPS-induced H9c2 cells compared with si-NC transfection (Fig. 3C). Moreover, compared with si-NC groups, silencing of NEAT1 significantly downregulated the levels of Bax and cleaved caspase- 3 and significantly upregulated Bcl-2 levels in LPS-induced H9c2 cells (Fig. 3D). In addition, the concentrations of TNF- $\alpha$, IL- 6 , IL- 8 and IL- $1 \beta$ were significantly decreased by NEAT1 knockdown in LPS-induced H9c2 cells compared with si-NC groups (Fig. 3E-H). These results suggested that NEAT1 may play a regulatory role in sepsis progression.

Overexpression of miR-590-3p attenuates LPS-induced H9c2 cell damage. By detecting the expression of miR-590-3p, it was found that miR-590-3p was significantly decreased in patients with sepsis and LPS-induced H9c2 cells compared with controls (Fig. 4A and B). Subsequently, gain-of-function experiments were performed using miR-590-3p mimic. Increased miR-590-3p expression confirmed the transfection efficiency of miR-590-3p mimic (Fig. S1B). Subsequently, miR-590-3p mimic was transfected into H9c2 cells, followed by LPS treatment. Compared to the LPS + miR-NC group, LPS + miR-590-3p group also markedly enhanced miR-590-3p expression, which further confirmed the transfection efficiency of the miR-590-3p mimic (Fig. 4C). CCK-8 assay results showed that miR-590-3p overexpression significantly enhanced the viability of LPS-induced H9c2 cells compared with the NC group (Fig. 4D). By measuring the number of apoptotic cells and the levels of apoptosis-related proteins, it was found that miR-590-3p mimic significantly suppressed the apoptosis; inhibited the levels of Bax and cleaved caspase-3; and increased Bcl-2 level in LPS-induced $\mathrm{H} 9 \mathrm{c} 2$ cells (Fig. 4E and F). In addition, the detection results of inflammatory cytokines showed that overexpression of miR-590-3p significantly decreased the concentrations of TNF- $\alpha$, IL-6, IL-8 and IL-1 $\beta$ in LPS-stimulated H9c2 cells compared with NC groups (Fig. 4G-J). It was found that LPS promoted the expression of TRAF6, while miR-590-3p also inhibited TRAF6 expression in LPS-induced H9c2 cells compared with the NC group (Fig. S2). Therefore, the data 
A

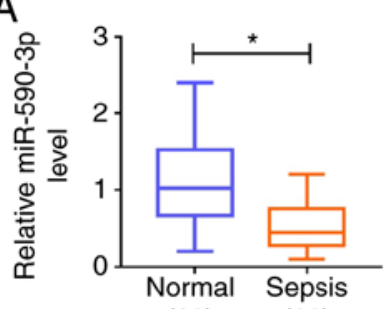

(22)

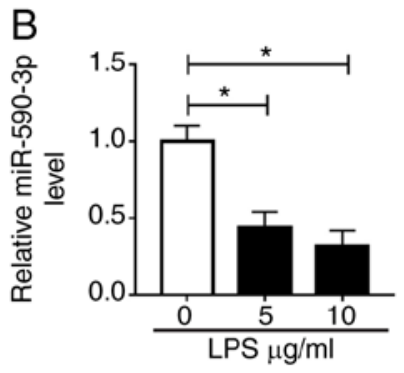

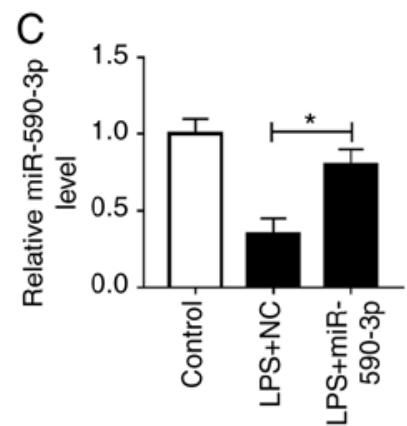

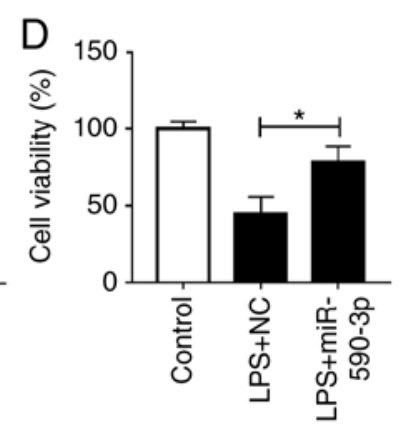

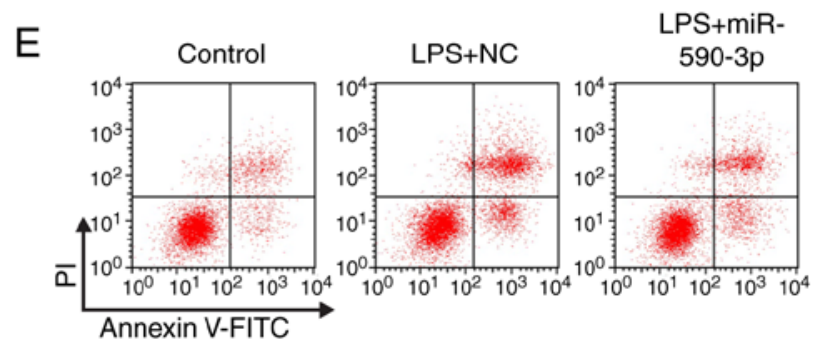
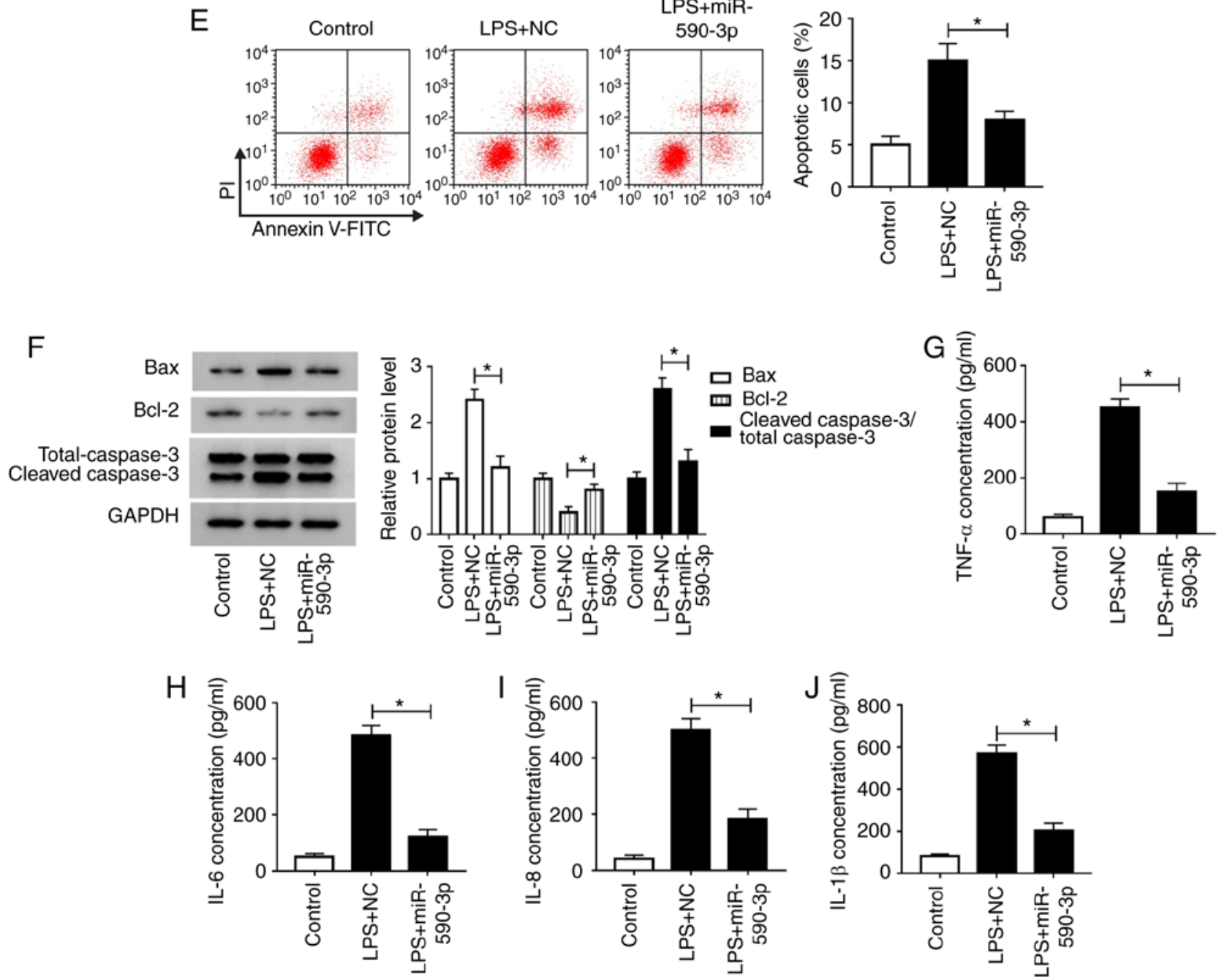

Figure 4. miR-590-3p overexpression attenuates LPS-induced H9c2 cell damage. (A) miR-590-3p expression in patients with sepsis and healthy volunteers was detected by RT-qPCR. (B) RT-qPCR was employed to measure miR-590-3p expression in H9c2 cells treated with LPS at different concentrations. H9c2 cells were transfected with miR-590-3p mimic or NC for $24 \mathrm{~h}$, followed by stimulation with LPS (10 $\mu \mathrm{g} / \mathrm{ml}) \mathrm{for} 12 \mathrm{~h}$. (C) miR-590-3p levels were detected using RT-qPCR. Cell viability, apoptosis and apoptosis-related protein expression of cells were determined using (D) CCK-8 assay, (E) flow cytometry and (F) western blot analysis, respectively. ELISA was performed to measure the concentrations of (G) TNF- $\alpha$, (H) IL-6, (I) IL-8 and (J) IL-1 $\beta$ in H9c2 cells. ${ }^{*} \mathrm{P}<0.05$. miR, microRNA; LPS, lipopolysaccharide; TNF, tumor necrosis factor; IL, interleukin; PI, propidium iodide; NC, negative control; RT-qPCR, reverse transcription-quantitative PCR.

indicated that miR-590-3p might play an inhibitory role in sepsis progression.

NEAT1 directly interacts with miR-590-3p. To investigate the association between NEAT1 and miR-590-3p, bioinformatics analysis was performed. The StarBase v2.0 tool predicted that miR-590-3p had binding sites with NEAT1 (Fig. 5A NEAT1-wt and NEAT1-mut plasmids were constructed for dual-luciferase reporter assays. The results revealed that miR-590-3p mimic significantly inhibited the luciferase activity of NEAT1-wt compared with the NC group, while showing no effects on NEAT1-mut (Fig. 5B). In addition, RIP assay showed that the enrichment of NEAT1 and miR-590-3p significantly increased in anti-Ago 2 groups compared with anti-IgG groups (Fig. 5C). RNA pull-down assay results showed that NEAT1 was significantly enriched in Bio-miR-590-3p compared 
A NEAT1-wt $\quad 5^{\prime}$-ttgtggtcactGTAAAATTa -3'

miR-590-3p 3'-tgatcgaatatGTATTTTAAt -5'

NEAT1-mut $\quad 5^{\prime}$-ttgtggtcacTGATTTTAAa -3'
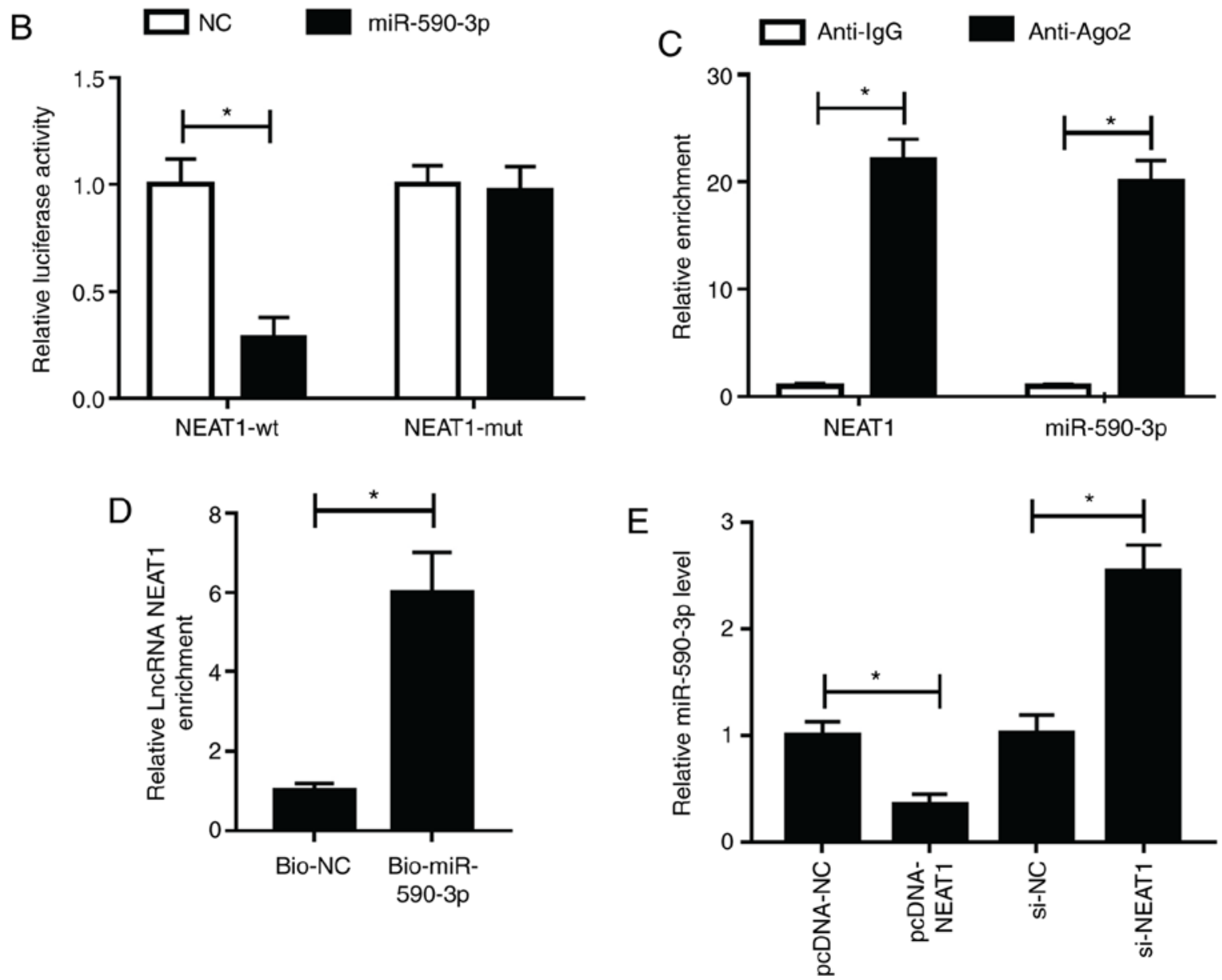

Figure 5. NEAT1 directly interacts with miR-590-3p. (A) Binding sites between NEAT1 and miR-590-3p. (B) The luciferase activity of NEAT1-wt and NEAT1-mut was detected using dual-luciferase reporter assay. (C) RNA immunoprecipitation assay was performed to measure the enrichment of NEAT1 or miR-590-3p in anti-Ago2 and anti-IgG. (D) RNA pull-down assay was used to verify the relationship between NEAT1 and miR-590-3p. (E) miR-590-3p expression was measured using reverse transcription-quantitative PCR to evaluate the effect of NEAT1 expression on miR-590-3p expression. ${ }^{*} \mathrm{P}<0.05$. miR, microRNA; NEAT1, nuclear enriched abundant transcript 1; wt, wild-type; mut, mutant; NC, negative control; IgG, immunoglobulin G; lncRNA, long non-coding RNA.

with Bi-NC (Fig. 5D), indicating that NEAT1 could interact with miR-590-3p. To further confirm this, pcDNA3.1 overexpressing NEAT1 vector was constructed and its transfection efficiency was confirmed (Fig. S1A). miR-590-3p expression was detected and it was found that NEAT1 overexpression significantly decreased miR-590-3p expression, while NEAT1 inhibition resulted in the opposite effects (Fig. 5E). Hence, the results revealed that NEAT1 could sponge miR-590-3p.

miR-590-3p inhibitor reverses the inhibitory effect of NEATI knockdown on LPS-induced H9c2 cells. To further investigate whether NEAT1 regulated sepsis progression by targeting miR-590-3p, anti-miR-590-3p was used to perform rescue experiments. Decreased miR-590-3p expression confirmed that miR-590-5p transfection was successful (Fig. S1B). Subsequently, si-NEAT1 and anti-miR-590-3p were co-transfected into H9c2 cells. Through measuring the expression of miR-590-3p, it was found that anti-miR-590-3p could reverse the promotive effects of NEAT1 silencing on miR-590-3p expression, indicating that the transfection efficiency of si-NEAT1 and anti-miR-590-3p was successful (Fig. 6A). CCK-8 assay results revealed that miR-590-3p inhibitor reversed the increasing effect of NEAT1 knockdown on the viability of LPS-induced H9c2 cells (Fig. 6B). Additionally, the suppressive effects of NEAT1 silencing on the apoptosis of LPS-induced H9c2 cells could be reversed by miR-590-3p inhibitor, as demonstrated by detection of apoptotic cells and the levels of Bax, Bcl-2 and cleaved caspase 3 (Fig. 6C and D). Similarly, miR-590-3p inhibitor also recovered the inhibitory effects of silenced NEAT1 on the concentrations of TNF- $\alpha$, IL-6, IL- 8 and IL-1 $\beta$ in LPS-induced H9c2 cells (Fig. 6E-H). These results revealed that NEAT1 regulated sepsis progression by sponging miR-590-3p. 


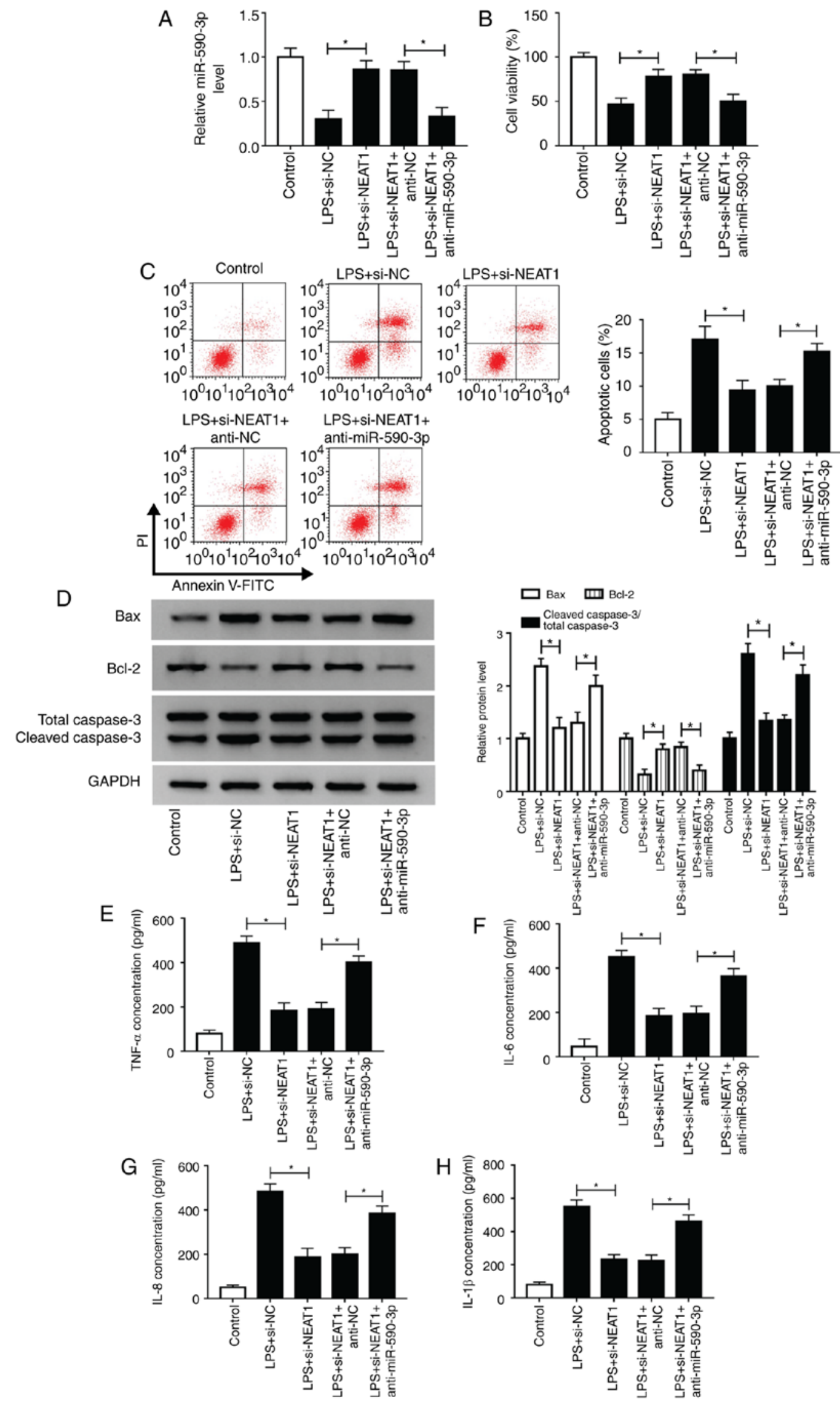

Figure 6. miR-590-3p inhibitor reverses the inhibitory effect of NEAT1 knockdown on LPS-induced H9c2 cells. H9c2 cells were transfected with si-NEAT1 and anti-miR-590-3p or their corresponding negative controls (si-NC and anti-NC), followed by treatment with LPS. (A) miR-590-3p expression was detected using reverse transcription-quantitative PCR to evaluate the transfection efficiency of si-NEAT1 and anti-miR-590-3p. (B) Cell Counting Kit-8 assay, (C) flow cytometry and (D) western blot analysis were employed to assess the viability, apoptosis and apoptosis-related protein expression of H9c2 cells, respectively. The concentrations of (E) TNF- $\alpha$, (F) IL-6, (G) IL-8 and (H) IL-1 $\beta$ were assessed using ELISA. "P $<0.05$. miR, microRNA; LPS, lipopolysaccharide; TNF, tumor necrosis factor; IL, interleukin; PI, propidium iodide; NC, negative control; si-NEAT1, small interfering RNA targeting NEAT1. 

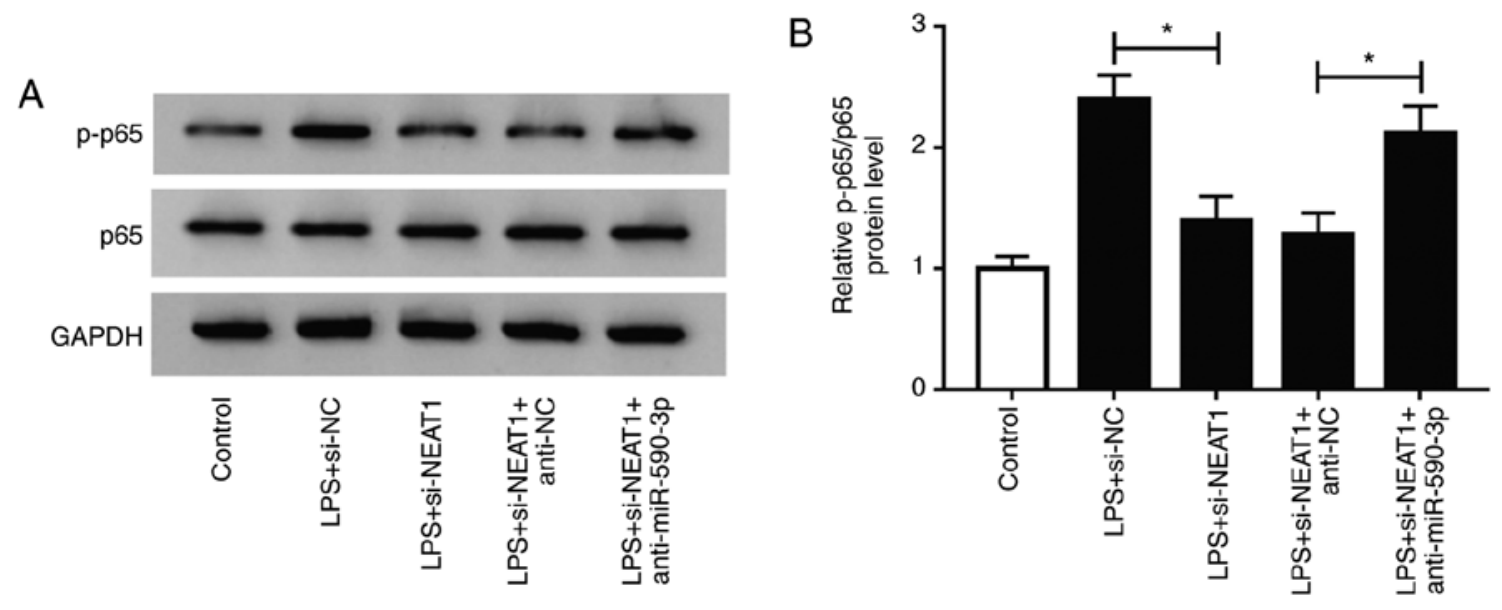

Figure 7. Inhibition of NEAT1 suppresses the NF- $x$ B signaling pathway via targeting miR-590-3p. H9c2 cells were transfected with si-NEAT1 and anti-miR-590-3p or their corresponding negative controls (si-NC and anti-NC), followed by treatment with LPS. (A) The protein levels of NF- $x \mathrm{~B}$ pathway-related factors p-p65 and p65 were detected and (B) quantified using western blot analysis. "P $<0.05$. NEAT1, nuclear enriched abundant transcript 1; miR, microRNA; si-NEAT1, small interfering RNA targeting NEAT1; LPS, lipopolysaccharide; p, phosphorylated.

Inhibition of NEAT1 suppresses the $N F-\kappa B$ signaling pathway via targeting miR-590-3p. It was reported that NF- $\mathrm{\kappa B}$ signaling pathway plays an important role in mediating inflammatory response and cell apoptosis (31). The present study investigated the effects of NEAT1 and miR-590-3p on the activity of the NF- $\kappa B$ signaling pathway in LPS-induced $\mathrm{H} 9 \mathrm{c} 2$ cells. Compared with the si-NC group, NEAT1 knockdown inhibited p-p65/p65 levels in LPS-induced H9c2 cells. In addition, miR-590-3p inhibitor also reversed the inhibitory effects of NEAT1 knockdown on p-p65/p65 levels (Fig. 7A and B). These results indicated that the NEAT1/miR-590-3p axis could regulate the activity of the NF- $\mathrm{KB}$ signaling pathway in LPS-induced H9c2 cells.

\section{Discussion}

Sepsis is a common complication resulting from severe trauma, burns, infection and major surgical operations, which can lead to multiple organ dysfunction syndromes in severe cases (1-3). Therefore, it is urgent to elucidate the molecular mechanism that affects the sepsis progression. The present study found that NEAT1 was highly expressed in sepsis. In addition, the sepsis cell model was constructed using LPS, and it was found that NEAT1 deficiency alleviated apoptosis and inflammatory response of cardiomyocytes induced by LPS, which provided a way to inhibit the progress of sepsis. Consistent with the results of previous studies, the present study showed that NEAT1 might be an effective target for the treatment of sepsis (12-15).

The involvement of miR-590-3p in inflammatory responses has been previously reported. He et al (32), showed that miR-590 decreased the levels of pro-inflammatory cytokines TNF- $\alpha$, MCP-1, IL-1b and IL-6 via targeting lipoprotein lipase. Moreover, Li et al (33), showed that inhibition of miR-590-3p improved the levels of IL-18 in osteoblasts. The present study found that miR-590-3p was downregulated in sepsis, and miR-590-3p could relieve LPS-induced cardiomyocyte damage. Additionally, miR-590-3p also decreased TRAF6 expression in LPS-induced cardiomyocytes.
Ma et al (34), discovered that miR-590-3p could suppress LPS-induced acute kidney injury by targeting TRAF6. Therefore, it was hypothesized that miR-590-3p might also regulate the progression of sepsis by targeting TRAF6, which requires further investigation. The present study also found that NEAT1 could serve as a sponge of miR-590-3p, and rescue experiments confirmed that NEAT1 mediated the regulation of cardiomyocyte damage by regulating miR-590-3p. Considering the important role of the NF- $\kappa B$ signaling pathway in inflammatory response (35), the activity of the NF- $\mathrm{KB}$ signaling pathway was assessed and it was confirmed that NEAT1/miR-590-3p could regulate the activity of the NF- $\mathrm{BB}$ signaling pathway. Similar to previous studies, the regulatory role of miR-590-3p and the NF- $\kappa B$ signaling pathway has also been confirmed in our study (24-25). However, studies have also shown that miR-590-3p inhibited the activity of the NF- $\kappa \mathrm{B}$ signaling pathway in peritoneal macrophages (24) and mice primary cardiomyocytes (25). Therefore, the role of the miR-590-3p/NF- $\mathrm{BB}$ signaling pathway in other heart or myocardial cell lines will be the focus of further research.

LncRNAs regulates gene expression via multiple mechanisms in various biological processes, including apoptosis, inflammatory response, cell differentiation and development (36-38). It was reported that IncRNA metastasis associated lung adenocarcinoma transcript 1 could be used as a therapeutic target for patients with sepsis (39). Chen et al (40), showed that lncRNAs urothelial carcinoma associated 1 and highly up-regulated in liver cancer were involved in the inflammatory response of LPS-induced endothelial cells. NEAT1 is a noncoding transcript with a length of $\sim 4 \mathrm{~kb}$ and is also involved in the regulation of sepsis (11-15). In the present study, the NEAT1 knockdown and miR-590-3p mimic transfection showed promising effects in alleviating LPS-induced cardiomyocyte damage. This showed that NEAT1 could be used as a biomarker IncRNA to evaluate sepsis progression, and NEAT1 inhibition or miR-590-3p mimic could provide a method for the treatment of sepsis. 
In summary, the present study suggested that NEAT1 plays a promotive role in sepsis progression by sponging miR-590-3p. This is a novel mechanism by which NEAT1 acts on the progression of sepsis. The inhibitory effects of NEAT1 knockdown and miR-590-3p overexpression on LPS-induced cardiomyocyte damage can provide new strategies for the clinical treatment of sepsis. Hence, the discovery of the NEAT1/miR-590-3p axis may contribute to the development of new treatments for sepsis.

\section{Acknowledgements}

Not applicable.

\section{Funding}

This study was supported by the Hunan Provincial Department of Education Science Research Fund (grant no. 18C0426) - Effect of hydrogen sulfide on mitochondrial damage of myocardial cells in septic rats.

\section{Availability of data and materials}

The datasets used and/or analyzed during the current study are available from the corresponding author on reasonable request.

\section{Authors' contributions}

LL and ZY conceived, designed and revised the present study. FL and ZS analyzed the data and wrote the manuscript. ZP and TY analyzed the data. All authors read and approved the final manuscript.

\section{Ethics approval and consent to participate}

The present study was approved by the Ethics Committee of The First Affiliated Hospital of the University of South China. Written informed consent forms was obtained from each patient.

\section{Patient consent for publication}

Not applicable.

\section{Competing interests}

The authors declare that they have no competing interests.

\section{References}

1. Napolitano LM: Sepsis 2018: Definitions and Guideline Changes. Surg Infect (Larchmt) 19: 117-125, 2018.

2. Delano MJ and Ward PA: Sepsis-induced immune dysfunction: Can immune therapies reduce mortality? J Clin Invest 126: 23-31, 2016.

3. Hotchkiss RS, Moldawer LL, Opal SM, Reinhart K, Turnbull IR and Vincent JL: Sepsis and septic shock. Nat Rev Dis Primers 2: 16045, 2016.

4. Stevenson EK, Rubenstein AR, Radin GT, Wiener RS and Walkey AJ: Two decades of mortality trends among patients with severe sepsis: A comparative meta-analysis". Crit Care Med 42: 625-631, 2014.

5. Sheng X, Zuo X, Liu X, Zhou Y and Sun X: Crosstalk between TLR4 and Notch1 signaling in the IgA nephropathy during inflammatory response. Int Urol Nephrol 50: 779-785, 2018.
6. Wang S, Li Z, Chen Q, Wang L, Zheng J, Lin Z and Li W: NF-kappaB-induced microRNA-211 inhibits interleukin-10 in macrophages of rats with lipopolysaccharide-induced acute respiratory distress syndrome. Cell Physiol Biochem 45: 332-342, 2018.

7. Boon RA, Jaé N, Holdt L and Dimmeler S: Long noncoding RNAs: From clinical genetics to therapeutic targets? J Am Coll Cardiol 67: 1214-1226, 2016.

8. Mohanty V, Gökmen-Polar Y, Badve S and Janga SC: Role of lncRNAs in health and disease-size and shape matter. Brief Funct Genomics 14: 115-129, 2015.

9. Qian K, Liu G, Tang Z, Hu Y, Fang Y, Chen Z and Xu X: The long non-coding RNA NEAT1 interacted with miR-101 modulates breast cancer growth by targeting EZH2. Arch Biochem Biophys 615: 1-9, 2017.

10. Chakravarty D, Sboner A, Nair SS, Giannopoulou E, Li R, Hennig S, Mosquera JM, Pauwels J, Park K, Kossai M, et al: The oestrogen receptor alpha-regulated lncRNA NEAT1 is a critical modulator of prostate cancer. Nat Commun 5: 5383, 2014.

11. Chen JX, Xu X and Zhang S: Silence of long noncoding RNA NEAT1 exerts suppressive effects on immunity during sepsis by promoting microRNA-125-dependent MCEMP1 downregulation. IUBMB Life 71: 956-968, 2019.

12. Liu WQ, Wang YJ, Zheng Y and Chen X: Effects of long non-coding RNA NEAT1 on sepsis-induced brain injury in mice via NF-кB. Eur Rev Med Pharmacol Sci 23: 3933-3939, 2019.

13. Huang Q, Huang C, Luo Y, He F and Zhang R: Circulating lncRNA NEAT1 correlates with increased risk, elevated severity and unfavorable prognosis in sepsis patients. Am J Emerg Med 36: 1659-1663, 2018.

14. Chen Y, Qiu J, Chen B, Lin Y, Chen Y, Xie G, Qiu J, Tong H and Jiang D: Long non-coding RNA NEAT1 plays an important role in sepsis-induced acute kidney injury by targeting miR-204 and modulating the NF- $\mathrm{BB}$ pathway. Int Immunopharmacol 59: 252-260, 2018.

15. Huang S, Qian K, Zhu Y, Huang Z, Luo Q and Qing C: Diagnostic value of the lncRNA NEAT1 in peripheral blood mononuclear cells of patients with sepsis. Dis Markers 2017: 7962836, 2017.

16. Bartel DP: MicroRNAs: Target recognition and regulatory functions. Cell 136: 215-233, 2009.

17. Stefani G and Slack FJ: Small non-coding RNAs in animal development. Nat Rev Mol Cell Biol 9: 219-230, 2008.

18. Cao X, Zhang C, Zhang X, Chen Y and Zhang H: miR-145 negatively regulates TGFBR 2 signaling responsible for sepsis-induced acute lung injury. Biomed Pharmacother 111: 852-858,

19. Ma Y, Liu Y, Hou H, Yao Y and Meng H: miR-150 predicts survival in patients with sepsis and inhibits LPS-induced inflammatory factors and apoptosis by targeting NF- $\kappa \mathrm{B} 1$ in human umbilical vein endothelial cells. Biochem Biophys Res Commun 500: 828-837, 2018.

20. Yao Y, Sun F and Lei M: miR-25 inhibits sepsis-induced cardiomyocyte apoptosis by targetting PTEN. Biosci Rep 38: $38,2018$.

21. Salem M, O'Brien JA, Bernaudo S, Shawer H, Ye G, Brkić J, Amleh A, Vanderhyden BC, Refky B, Yang BB, et al: miR-590-3p promotes ovarian cancer growth and metastasis via a novel FOXA2-versican pathway. Cancer Res 78: 4175-4190, 2018.

22. Rohini M, Gokulnath M, Miranda PJ and Selvamurugan N: miR-590-3p inhibits proliferation and promotes apoptosis by targeting activating transcription factor 3 in human breast cancer cells. Biochimie 154: 10-18, 2018.

23. Du B, Wang T, Yang X, Wang J, Shi X, Wang X, Wu D, Feng L, Chen L and Zhang W: SOX9, miR-495, miR-590-3p, and miR-320d were identified as chemoradiotherapy-sensitive genes and miRNAs in colorectal cancer patients based on a microarray dataset. Neoplasma 66: 8-19, 2019.

24. Zhao S, Yang G, Liu PN, Deng YY, Zhao Z, Sun T, Zhuo XZ, Liu JH, Tian Y, Zhou J, et al: miR-590-3p Is a novel microRNA in myocarditis by targeting nuclear factor kappa-b in vivo. Cardiology 132: 182-188, 2015.

25. Zhao C, Jiang J, Wang YL and Wu YQ: Overexpression of microRNA-590-3p promotes the proliferation of and inhibits the apoptosis of myocardial cells through inhibition of the NF- $\kappa B$ signaling pathway by binding to RIPK1. J Cell Biochem 120: 3559-3573, 2019.

26. Xu L, Wu Q, Zhou X, Wu Q and Fang M: TRIM13 inhibited cell proliferation and induced cell apoptosis by regulating NF- $\kappa B$ pathway in non-small-cell lung carcinoma cells. Gene 715: $144015,2019$. 
27. Qi R, Huang J, Wang Q, Liu H, Wang R, Wang J and Yang F. MicroRNA-224-5p regulates adipocyte apoptosis induced by $\mathrm{TNF} \alpha$ via controlling NF- $\kappa \mathrm{B}$ activation. J Cell Physiol 233: 1236-1246, 2018.

28. Zhang H, Li H, Ge A, Guo E, Liu S, Zhang L: Long non-coding RNA TUG1 inhibits apoptosis and inflammatory response in LPS-treated H9c2 cells by down-regulation of miR-29b. Biomed Pharmacother 101: 663-669, 2018.

29. Yao Y, Xu K, Sun Y, Tian T, Shen W, Sun F, Yuan W, Wu H, Chen G, Yuan L, et al: MiR-215-5p inhibits the inflammation injury in septic H9c2 by regulating ILF3 and LRRFIP1. Int Immunopharmacol 78: 106000, 2020.

30. Livak KJ and Schmittgen TD: Analysis of relative gene expression data using real-time quantitative PCR and the 2(-Delta Delta C(T)) Method. Methods 25: 402-408, 2001.

31. Song B, Wang Z, Liu Y, Xu S, Huang G, Xiong Y, Zhang S, Xu L, Deng $X$ and Guan S: Immunosuppressive activity of daphnetin, one of coumarin derivatives, is mediated through suppression of NF- $\kappa \mathrm{B}$ and NFAT signaling pathways in mouse T cells. PLoS One 9: e96502, 2014.

32. He PP, Ouyang XP, Tang YY, Liao L, Wang ZB, Lv YC, Tian GP, Zhao GJ, Huang L, Yao F, et al: MicroRNA-590 attenuates lipid accumulation and pro-inflammatory cytokine secretion by targeting lipoprotein lipase gene in human THP-1 macrophages. Biochimie 106: 81-90, 2014.

33. Li TM, Liu SC, Huang YH, Huang CC, Hsu CJ, Tsai CH, Wang SW and Tang CH: YKL-40-Induced Inhibition of miR-590-3p promotes interleukin-18 expression and angiogenesis of endothelial progenitor cells. Int J Mol Sci 18: 18, 2017.
34. Ma J, Li YT, Zhang SX, Fu SZ and Ye XZ: miR-590-3p attenuates acute kidney injury by inhibiting tumor necrosis factor receptor-associated factor 6 in septic mice. Inflammation 42: 637-649, 2019

35. Karin M: NF-kappaB as a critical link between inflammation and cancer. Cold Spring Harb Perspect Biol 1: a000141, 2009.

36. Rossi MN and Antonangeli F: LncRNAs: New players in spoptosis control. Int J Cell Biol 2014: 473857, 2014

37. Mirza AH, Berthelsen CH, Seemann SE, Pan X, Frederiksen KS, Vilien M, Gorodkin J and Pociot F: Transcriptomic landscape of lncRNAs in inflammatory bowel disease. Genome Med 7: 39, 2015.

38. Fatica A and Bozzoni I: Long non-coding RNAs: New players in cell differentiation and development. Nat Rev Genet 15: 7-21, 2014.

39. Geng F, Liu W and Yu L: Potential role of circulating long noncoding RNA MALAT1 in predicting disease risk, severity, and patients' survival in sepsis. J Clin Lab Anal 33: e22968, 2019.

40. Chen Y, Fu Y, Song YF and Li N: Increased expression of lncRNA UCA1 and HULC is required for pro-inflammatory response during LPS induced sepsis in endothelial cells. Front Physiol 10: 608, 2019.

This work is licensed under a Creative Commons Attribution-NonCommercial-NoDerivatives 4.0 International (CC BY-NC-ND 4.0) License. 